\title{
A cost-effectiveness study of the management of intractable urinary incontinence by urinary catheterisation or incontinence pads
}

\author{
Marion E T McMurdo, Peter G Davey, Margaret-Anne Elder, Ruth M Miller, David C Old, \\ Mo Malek
}

\begin{abstract}
Study objective-The aim was to compare the costs and effects of management of intractable urinary incontinence by urinary catheterisation or incontinence pads.

Design-This was a prospective, randomised study comparing catheterisation with pads, supplemented by additional data collected from patients with chronic indwelling catheters. Main outcome measures were costs of equipment, nursing time, patient preference, nursing preference, and clinical and bacteriological assessment of urinary infection.

Subjects-78 intractably incontinent elderly female patients were randomly allocated to management by urinary catheter or pads and toileting. Supplementary data on equipment costs and nursing time were collected from 27 patients, of whom 22 were already catheterised at the time of the randomisation and five were catheterised by the nursing staff after the last date for entry into the randomisation.
\end{abstract}

Main results-Of the 38 patients randomised to catheterisation, 14 refused consent so only 24 were catheterised on day 1 of the study. There was a rapid removal of catheters, especially in the first six weeks of the study and only four of the randomised catheter patients completed the full 26 weeks of the study. However, eight of the pads patients were catheterised between the 7 th and 22 nd week because of deteriorating general condition and all retained their catheters for the remainder of the study period. Of 35 patients who had experienced catheters and pads, 12 expressed a clear preference for catheters, 12 for pads, and 11 were undecided. Nurses were in favour of the use of pads, mainly because of concerns about urinary infection with catheters. Comparing costs for patients managed with catheters (532 patient weeks) or pads (903 patient weeks), catheter patients required less nursing time $(15.4 v 29.0 \mathrm{~h}$ per patient per week) but equipment costs were higher $(£ 19 \cdot 20-24.65 v \notin 8 \cdot 79-11.35$ per patient per week), mainly because of the cost of catheter care ( $£ 12.75$ per patient per week). Asymptomatic bacteriuria was prevalent in both groups but $73 \%$ of catheterised patients received treatment for clinical signs of infection compared with $40 \%$ of pads patients. Only $30 \%$ of patients who were treated had any generalised symptoms of infection.
Conclusions-Use of catheters reduces nursing time but may increase weekly equipment costs depending on the cost of laundry. Despite the high dropout rate among patients randomised to catheters a minority of patients $(12 / 35)$ expressed a clear preference for catheters and we believe that more patients with intractable incontinence should be given a trial of catheterisation to assess acceptability. Bacteriuria was prevalent in pads or catheter patients but no major episodes of invasive infection were noted in either group.

Urinary incontinence in the elderly is prevalent, costly, and neglected. While it affects $5-15 \%$ of elderly people living in the community, ${ }^{1}$ its prevalence increases from approximately $40 \%$ in hospital inpatients ${ }^{2}$ to over $50 \%$ in institutionalised populations. ${ }^{3}$ Independent risk factors for incontinence include neurological impairment, immobility, and female sex but not chronic bacteriuria or advanced age. ${ }^{4}$ The costs of incontinence are medical (urinary tract infection, pressure sores, perineal rashes, and falls); psychosocial (embarassment, isolation, depression, and predisposition to institutionalisation) ${ }^{67}$; and economic. $^{89}$

The predominant causes of urinary incontinence in the female institutionalised elderly patient are detrusor hyperreflexia, stress incontinence, and underactive detrusor. ${ }^{10}$ Correctable causes such as urinary tract infection and constipation are found in only a minority of cases.

Two basic approaches to the management of chronic urinary incontinence exist. First there is the use of incontinence pads and regular toileting. However difficulties arise with skin erythema over the sacral region, resulting from contact with ammoniacal urine and leading perhaps to pressure sores. Second there is urinary catheterisation, which effectively eliminates the skin problems mentioned above. However, because an indwelling catheter is a foreign body, the risk of bacteriuria is great. Patients with long term catheters usually have bacteriuria and often with a mixture of organisms. ${ }^{11}$ Although the costs of asymptomatic bacteriuria in the elderly catheterised patient have not been adequately quantified, they may include urinary tract infection, increased use of antibacterial drugs, and consequent development of resistance among bacteria, or superinfection of patients by toxin producing Clostridium difficile. ${ }^{12}$ 
A cost-effectiveness study was therefore designed to compare the effects of managing intractable urinary incontinence by catheterisation or by pads on patient morbidity, nursing time and preference, and overall hospital costs.

\begin{abstract}
Methods
PATIENTS

The study was approved by the Tayside committee on medical ethics. At the start of the study, there were present in nine long stay geriatric wards in two Dundee hospitals a total of 173 patients, 119 of whom met the study definition of incontinence, ie, "incontinent of urine at least twice daily for 2-3 weeks despite a search for remediable causes". Among the latter, 41 patients were excluded from the randomisation exercise because they had urinary catheters already in situ; showed previous signs of urinary catheter intolerance; or had incontinence less frequently than in the above definition. The remaining 78 elderly female patients eligible for inclusion in our study were allocated to two management groups-38 to catheterisation and 40 to use of pads-by block randomisation, with each block containing four patients and allocation within blocks being made from a random numbers table.
\end{abstract}

Each patient was assessed for cognitive function (MSQ), ${ }^{13}$ dependency level (Katz Activities of Daily Living score), ${ }^{14}$ and risk of skin breakdown (Norton score). ${ }^{15}$ Katz and Norton Scores were repeated monthly.

Patients randomised to urinary catheterisation were asked to give informed written consent after explanation of the catheterisation procedure. If a patient's MSQ was <6/10, the patient's next of kin was asked to give consent on their behalf. A short female Foley catheter sized 12 or 14 was used, with $15-25 \mathrm{ml}$ sterile water instilled into the balloon.

Patients who became intolerant of catheterisation, who pulled on or pulled out their catheter or who developed haematuria (or other catheter related problems) were withdrawn from the study. Similarly, if a patient in the "pad" group became terminally ill or developed severe skin problems, a urinary catheter was inserted and the patient was withdrawn from the study.

All patients were asked via a questionnaire to state their preference between catheterisation or pads as a method of managing urinary incontinence; further questionnaires were given to each patient at 3 and 6 months. As new patients were admitted to the study wards, their eligibility for entry into the trial was assessed after a monitoring period of 3-4 weeks.

Because fewer catheter patients than pad patients were studied in the first 6 months, largely because of refusal of consent (see Results), it was decided to gather supplementary data on weekly equipment costs, weekly nursing time and other data from an additional 27 catheterised patients, of whom 22 were already catheterised at the time of the original randomisation and five were catheterised by nursing staff after the last date for entry into the randomisation procedure. These 27 (non-randomised) patients had been catheterised for 0 to 18 months.
INCONTINENCE CARE CHECKSHEETS

Nursing staff on wards recorded daily the following information:

(a) Catheter patients: the number of catheterisations; the number, type and method of bladder irrigations; the number of times patients' urine bags were checked/emptied or both; and the frequency of catheter care.

(b) Pads patients: the number of incontinence pads used; the frequency of toileting.

(c) Both groups of patients: the number of times vulval toileting was performed; the number of times clothes were changed or baths given due to urinary or faecal incontinence; the number and type of sacral or buttock dressings; the number and type of each application of cream or spray to the buttocks or groins; the number of items sent to the laundry as a result of incontinence.

\section{COSTING OF NURSING PROCEDURES}

One of us (MAE) observed 25 performances of each nursing procedure at the Royal Victoria Hospital or at Ashludie Hospital and recorded the number of nurses involved, the time taken for each procedure, and all items of equipment used. Costings of equipment and drugs were obtained from the Pharmacy Unit, Ninewells Hospital. Costings of nursing procedures were calculated by multiplying (the frequency of each procedure) $\times$ (nursing time $) \times$ (equipment cost).

\section{BACTERIOLOGY}

From each patient in the pads group, a "prestudy" dip slide specimen of "clean catch" urine was obtained and further specimens of urine were taken at monthly intervals thereafter. From each patient in the catheter group, a dip slide specimen of catheter urine (CSU) was obtained on the day of catheterisation and from further CSU specimens obtained monthly. The results of culture of the urine were not returned to the study wards. ${ }^{8}$

A pre-study specimen of faeces obtained from each patient was held in the refrigerator at $8^{\circ} \mathrm{C}$ and transported to the laboratory within $24 \mathrm{~h}$ of collection for culture for Clostridium difficile and, if appropriate, for toxin assay. Further specimens of faeces for examination for $C$ difficile and toxin assay were taken from any patients who developed diarrhoea of unknown cause.

\section{CLINICAL ASSESSMENT OF URINARY INFECTION}

Whenever a patient received antibacterial treatment for urinary infection, the prescribing doctor was asked to give the reasons for treatment; and the dose, duration, and route of administration of antibacterial therapy were recorded. These details were recorded from any catheterised patient from whom a precatheterisation urine sample and at least two subsequent monthly urine samples had been obtained for culture.

STATISTICAL METHODS

Standard methods were used for calculation of 95\% confidence intervals for means and proportions. Point estimations for medians and their $95 \%$ confidence intervals were calculated by the Wilcoxon signed rank test (Mintab Release $6 \cdot 1)$. 


\section{Results}

The characteristics of the patients at the time of entry to the study are shown in table I. There were no main differences in the characteristics of the patients in the two groups, which were well matched. Of the 38 patients randomised to catheterisation, 14 refused consent so that only 24 $(63 \%)$ were catheterised on day 1 of the study (figure). There was a rapid rate of removal of catheters, especially in the first 6 weeks of study and only four $(10 \%)$ of the randomised catheter patients completed the full 26 weeks of study. Eight $(20 \%)$ of the patients in the pads group were later catheterised by nursing staff because of deteriorating general conditions; all of these patients retained their catheters for the remainder of the study period (figure). Three patients, who originally refused consent for catheterisation, were subsequently catheterised by nursing staff; each had retained their catheters when data collection was competed 21 weeks later. Neither the Katz nor the Norton scores altered significantly during the study in either group.

During the study period 35 patients were identified who had experienced both catheters and pads and were capable of stating a preference. Twelve of them preferred catheters, 12 pads, and

Table I Patient characteristics in groups. Values are means (range)

Percentage of patients catheterised in catheter $(-)$ or pads (- - ) group with time

Table II Ranked frequency of incontinence procedures comparing patients using pads and all ${ }^{\mathrm{a}}$ catheterised patients

\begin{tabular}{|c|c|c|}
\hline Characteristic & $\begin{array}{l}\text { Pads } \\
(n=40)\end{array}$ & $\begin{array}{l}\text { Randomised catheter } \\
(n=38)\end{array}$ \\
\hline $\begin{array}{l}\text { Age } \\
\text { MSQ } \\
\text { Katz score } \\
\text { Norton score }\end{array}$ & $\begin{aligned} 87 & (76-95) \\
2 \cdot 4 & (0-9) \\
6 \cdot 7 & (3-7) \\
11 \cdot 3 & (8-18)\end{aligned}$ & $\begin{aligned} 84 & (72-100) \\
2 \cdot 6 & (0-10) \\
6 \cdot 6 & (3-7 \\
11 \cdot 4 & (5-17)\end{aligned}$ \\
\hline
\end{tabular}

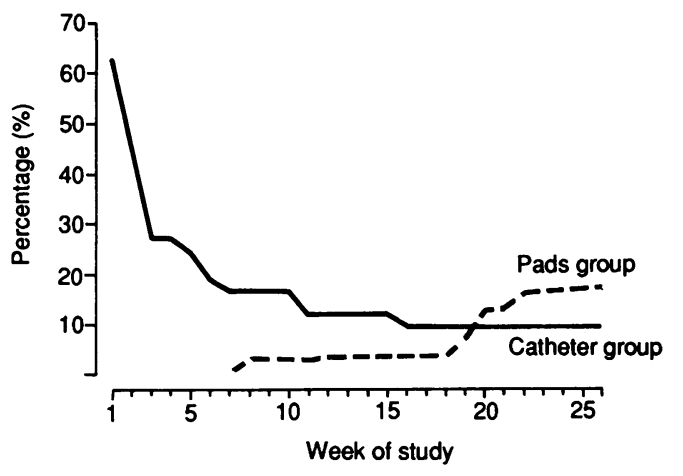

\begin{tabular}{|c|c|c|}
\hline Procedure & $\begin{array}{l}\text { Mean } \\
\text { frequency } \\
\text { per patient } \\
\text { per week }\end{array}$ & $\begin{array}{l}95 \% \text { confidence } \\
\text { intervals }\end{array}$ \\
\hline $\begin{array}{l}\text { Send laundry } \\
\text { Change incontinence pads } \\
\text { Toilet patient during day } \\
\text { Toilet patient during night } \\
\text { Change patient during night } \\
\text { Change patient during day } \\
\text { Others }\end{array}$ & $\begin{array}{l}\text { Pads group } \\
43.46 \\
33.91 \\
26.72 \\
19.73 \\
14.89 \\
11.01 \\
5.25\end{array}$ & $\begin{array}{r}42 \cdot 21-44 \cdot 71 \\
33 \cdot 13-34 \cdot 69 \\
26 \cdot 41-27 \cdot 03 \\
19 \cdot 51-19 \cdot 95 \\
14 \cdot 51-15 \cdot 27 \\
10 \cdot 51-11 \cdot 51 \\
4 \cdot 79-5 \cdot 70\end{array}$ \\
\hline $\begin{array}{l}\text { Send laundry } \\
\text { Empty bag during day } \\
\text { Empty bag during night } \\
\text { Change patient at night } \\
\text { Catheter care during night } \\
\text { Catheter care during day } \\
\text { Change patient during day } \\
\text { Change night bag during night } \\
\text { Change night bag during day } \\
\text { Apply cream } \\
\text { Others }\end{array}$ & $\begin{array}{l}\text { Catheter group } \\
24 \cdot 62 \\
20 \cdot 97 \\
17 \cdot 05 \\
9 \cdot 03 \\
8 \cdot 56 \\
8 \cdot 48 \\
6.74 \\
4.52 \\
3.93 \\
3 \cdot 37 \\
7 \cdot 11\end{array}$ & $\begin{array}{r}23 \cdot 69-25 \cdot 55 \\
20 \cdot 51-21 \cdot 43 \\
16 \cdot 69-17 \cdot 41 \\
8 \cdot 66-9 \cdot 40 \\
8 \cdot 27-8 \cdot 85 \\
8 \cdot 18-8 \cdot 78 \\
6 \cdot 13-7 \cdot 17 \\
4 \cdot 32-4 \cdot 72 \\
3 \cdot 72-4 \cdot 14 \\
3 \cdot 05-3 \cdot 69 \\
6 \cdot 07-8 \cdot 15\end{array}$ \\
\hline
\end{tabular}

${ }^{a} A l l$, ie, randomised and non-randomised, catheter patients b ${ }_{\text {The total numbers of patient weeks in the pads and catheter }}$ groups were 903 and 532, respectively the remaining 11 were undecided. The reasons given for preference were almost identical, being either better local comfort of a feeling of increased dignity. For example, statements from patients who preferred catheter included: "I like the tube, it keeps me dry" and "My relatives won't take me in their car when I'm wet". Statements from patients who preferred pads included: "I dislike the catheter and find it uncomfortable" and "Pads are comfortable and the catheter is painful". Some patients were equivocal; thus, "The catheter is a nuisance, although. I do not like wetting the bed".

The preferences of nursing staff reflected concern that catheterisation is an invasive procedure, increases the risk of urinary infection, and should be reserved for debilitated patients or patients with perineal/gluteal skin problems. Of interest, the proportion of nurses who did express a preference for catheter was higher for night staff than day staff $(39 \%$ versus $16 \%)$. Of the 140 nurses working on the study wards at the start of the study and 190 working on the study wards at the end of the study, the proportion who unequivocally preferred catheterisation for management of intractable urinary incontinence in females had not changed $(21 \%$ at the start of the study versus $22 \%$ at the end of the study). There was no detectable change in prevalence if the analysis was restricted to staff who had worked on the study wards throughout the study.

The data relating to frequency of incontinence procedures, equipment costs and nursing time are summarised in tables II-IV.

Among the procedures common to both patient management groups (table II), the most striking differences were seen in (1) the sending of laundry (sent 43 and 25 times per patient per week for pads and catheter patients, respectively) and (2) changing the patients during the night (15 and nine changes per patient per week for pads and catheter patients, respectively).

Within equipments costs (table III), the lower laundry costs in the catheter group $(£ 3.44$ per patient per week) were not sufficient to offset the cost of catheter related procedures, notably catheter care ( $£ 12.75$ per patient per week).

The frequency of procedures affecting the costs of nursing times has been separated for day and night (table IV), because of different staffing levels at these times. In contrast to equipment costs, nursing time (and cost) was unequivocally lower in the catheter group, and particularly so at night.

A total of 11 catheterised patients met the criteria for clinical assessment of urinary infection, six of them randomised and five nonrandomised (table V). The prevalence of bacteriuria was high in both groups (median proportions of culture positive urines were 0.7 and 1.0 in the pads and catheter patients respectively). Pre-catheterisation urine samples were culture positive in nine of 11 catheter patients $(82 \%)$. The proportion of patients treated by ward staff was also higher in the catheterised patients $(73 \%)$ than in the pads patients $(40 \%)$. The reasons for treatment were broadly similar in both groups (table V). The generalised symptoms attributed to bacteriuria were increased confusion in all 10 pads patients, 
whereas in the catheter patients the symptoms were somnolence or lethargy (three patients), vomiting (one patient), and fever (one patient).

No patient received intravenous antibacterial therapy for urinary infection and the maximum cost of a course of antibacterial therapy was $£ 24.00$ (table V).

During the study only eight faecal samples (five in the pads group and three in the catheter group) were positive for $C$ difficile, but no patients had diarrhoea in association with the isolation of $C$ difficile from their faeces.

\section{Discussion}

This study was initiated in response to the paper by Rannikko et $a l^{8}$ which concluded that catheterisation was more cost-effective than pads in the management of urinary incontinence. Unlike the study by Rannikko, our study was a randomised controlled trial and catheter tolerance was considered. In contrast to Rannikko's study, we found that the costs of equipment were higher in the catheterised patients. The major reason for this discrepancy is that costs of catheter care were not included by Rannikko et al, yet they account for $52-66 \%$ of the weekly equipment costs in our catheterised patients.

Table III Comparison of equipment costs among patients using pads and all catheterised patients

\begin{tabular}{|c|c|c|c|}
\hline \multirow[b]{2}{*}{ Equipment } & \multirow{2}{*}{$\begin{array}{l}\text { Cost }(£) \\
\text { per item }\end{array}$} & \multicolumn{2}{|c|}{ Cost $(£)$ per patient per week in group $b$} \\
\hline & & Pads & Catheter \\
\hline $\begin{array}{l}\text { Laundry } \\
\text { Change pads } \\
\text { Apply cream } \\
\text { Apply spray } \\
\text { Apply dressings } \\
\text { Catheter care } \\
\text { Change night bag } \\
\text { Change leg bag } \\
\text { Bladder lavage } \\
\text { Catheterisation }\end{array}$ & $\begin{array}{l}0 \cdot 14 \\
0 \cdot 07 \\
0 \cdot 04-0.72 \\
0 \cdot 32-0.54 \\
0 \cdot 19-1 \cdot 37 \\
0 \cdot 75 \\
0 \cdot 09 \\
0 \cdot 04 \\
0 \cdot 74-1 \cdot 09 \\
3 \cdot 81-8.68\end{array}$ & $\begin{array}{l}6 \cdot 09 \\
2 \cdot 37 \\
0 \cdot 12-2 \cdot 43 \\
0 \cdot 19-0 \cdot 32 \\
0 \cdot 02-0 \cdot 14 \\
- \\
- \\
- \\
-\end{array}$ & $\begin{array}{l}3 \cdot 44 \\
-\quad \\
0 \cdot 12-2 \cdot 43 \\
0 \cdot 48-0 \cdot 80 \\
0 \cdot 06-0 \cdot 41 \\
12 \cdot 75 \\
0 \cdot 77 \\
0 \cdot 14 \\
0 \cdot 30-0 \cdot 44 \\
1 \cdot 14-3 \cdot 47\end{array}$ \\
\hline All & & $8 \cdot 79-11 \cdot 35$ & $19 \cdot 20-24 \cdot 65$ \\
\hline
\end{tabular}

all, ie, randomised and non-randomised, catheter patients

b The cost per patient per week is calculated from the cost per item $\times$ mean frequency (see table II). Ranges are given for those procedures in which there was a variety in the type or amount of equipment used.

Table IV Comparison of nursing times for patients using pads and all ${ }^{\mathrm{a}}$ catheterised patients

\begin{tabular}{|c|c|c|}
\hline \multirow{2}{*}{$\begin{array}{l}\text { Procedure and } \\
\text { duty period }\end{array}$} & \multicolumn{2}{|c|}{$\begin{array}{l}\text { Mean nursing time in minutes per patient } \\
\text { per week (and confidence intervals) in group }\end{array}$} \\
\hline & Pads & Catheter \\
\hline $\begin{array}{l}\text { Toilet } \\
\text { Change patient } \\
\text { Bath } \\
\text { Empty bag } \\
\text { Catheter care } \\
\text { Change night bag } \\
\text { Change leg bag } \\
\text { Bladder lavage } \\
\text { Catheterise }\end{array}$ & $\begin{array}{rr}712 \cdot 9 & (606 \cdot 1-819 \cdot 7) \\
315 \cdot 7 & (250 \cdot 2-381 \cdot 2) \\
50 \cdot 4 & (43 \cdot 2-57 \cdot 6) \\
- & \\
- & \\
- & \\
- & \\
- & \end{array}$ & $\begin{array}{rr}\text { Day } & \\
23.2 & (19 \cdot 7-26 \cdot 7) \\
142.9 & (113.2-172.5) \\
57.9 & (49.6-66.2) \\
132.7 & (102.3-161.9) \\
72.8 & (56 \cdot 2-89.3) \\
23.4 & (22.0-25.0) \\
7.5 & (7 \cdot 1-8 \cdot 1) \\
7.5 & (5.6-9.4) \\
12.6 & (9.7-15.4)\end{array}$ \\
\hline $\begin{array}{l}\text { Toilet } \\
\text { Change patient } \\
\text { Bath } \\
\text { Empty bag } \\
\text { Catheter care } \\
\text { Change night bag } \\
\text { Change leg bag } \\
\text { Bladder lavage } \\
\text { Catheterise }\end{array}$ & $\begin{array}{l}388 \cdot 7(309 \cdot 8-467 \cdot 6) \\
269 \cdot 7(218 \cdot 0-321 \cdot 5) \\
1.3(1 \cdot 1-1 \cdot 5) \\
= \\
= \\
=\end{array}$ & $\begin{array}{rr}\text { Night } & \\
16.9 & (13.5-20.4) \\
221.2 & (178.8-263.7) \\
1.3 & (1.1-1.5) \\
107.9 & (83.2-131.6) \\
72.8 & (56.2-89.3) \\
23.4 & (22.0-25.0) \\
0.5 & (0.4-0.5) \\
1.4 & (1.1-1.7) \\
1.4 & (1.1-1.7)\end{array}$ \\
\hline $\begin{array}{l}\text { Day } \\
\text { Night }\end{array}$ & $\begin{array}{cl} & \text { All }(h \\
18.0 & (15.0-21.0) \\
11.0 & (8.8-13.2)\end{array}$ & $\begin{aligned} & \text { er patient per week) } \\
& 8.0 \quad(6.4-9.6) \\
& 7.4 \quad(6.0-8.9)\end{aligned}$ \\
\hline Both & $29.0 \quad(23.8-34 \cdot 2)$ & $15.4 \quad(12.4-18.5)$ \\
\hline
\end{tabular}

${ }^{a} \mathrm{All}, \mathrm{ie}$, randomised and non-randomised, catheter patients
The remaining weekly costs were remarkably similar in the two studies, even allowing for changes in prices between 1985 and $1988 / 89$. The respective costs per patient per week for items included by Rannikko et al and by the present study (table III) were: among pads patients, the costs of continence pads $£ 2 \cdot 42$ versus $£ 2 \cdot 37$; among catheter patients, the costs of catheterisation $£ 0.83$ versus $£ 1 \cdot 14-£ 3.47$; urine bags $£ 0.51$ versus $£ 0.91$; and irrigiation $£ 0.12$ versus $£ 0 \cdot 30-£ 0 \cdot 44$.

Table $V$ Clinical data about urinary infection for patients using pads and all patients who were catheterised $^{\mathrm{a}}$

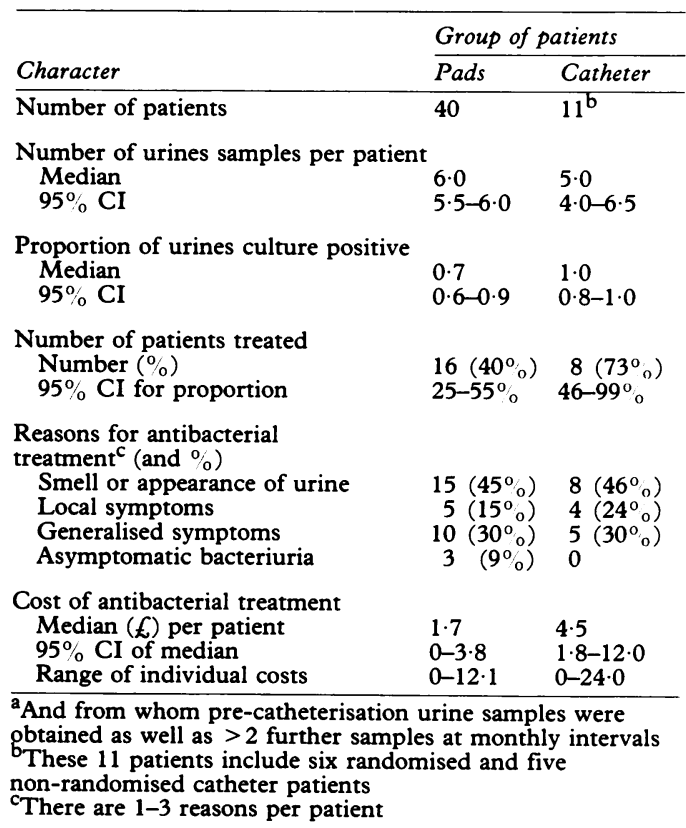

Our conclusions about weekly equipment costs are profoundly sensitive to assumptions about the cost of laundry. The figure of $£ 0 \cdot 12$ is a notional cost used by the Scottish Home and Health Department for sending one batch of laundry (irrespective of number of items in the batch; D Clark, personal communication). The laundry at Ninewells Hospital serves most of the hospitals in Tayside and it is unlikely that a $50 \%$ reduction in laundry from the continuing care wards would have a noticeable input in the running costs of the laundry. If the cost of sending laundry in a particular hospital were $£ 0.98$ per batch, then the weekly equipment costs would be $£ 45 \cdot 29-£ 47 \cdot 85$ for pads patients and $£ 39.98-£ 45.34$ for catheter patients. If laundry were being sent to a private company then it is likely that laundry costs would exceed the $£ 0.98$ per batch required for weekly equipment costs in pads patients to exceed those in catheter patients. The data in tables II and III should therefore be interpreted with reference to local costs for sending items of laundry.

Like previous investigators, ${ }^{8}$ we found that catheterised patients required much less nursing time per patient per week than pads patients. Rannikko et $a l^{8}$ did not discriminate between nursing times during the day or night. Our finding that savings are greater at night is important because staffing levels are lower at night. Indeed, it is interesting that night nurses already expressed a stronger preference for catheterisation before the study started. One of 
the patients stated that her ideal would be to wear pads during the day and have a catheter at night but this is unlikely ever to be a practical proposition.

Our data on urinary infection are seriously flawed by the small number (six) of randomised catheter patients who fulfilled the criteria for this part of the study. Pre-catheterisation urinary specimens were culture positive in a high proportion (9/11) of the patients available for study. Although we could not detect any differences in Katz scores between these patients and those in the pads group, it remains possible that patients who retain catheters are more dependent and more likely to have bacteriuria and that the catheter is a marker for bacteriuria rather than its cause. Obtaining pre-catheterisation urine samples from a larger number of patients may help to clarify this issue. Although our data do not allow us to attribute causality, catheterisation was associated with an increased prevalence of bacteriuria and antimicrobial therapy. However, no patient required intravenous treatment and no deaths were associated with these episodes. The overall cost of antimicrobial treatment was small. The prevalence of contamination with $C$ difficile was surprisingly low in comparison with other studies ${ }^{16}$ and antibiotic associated colitis was not observed during the present study.

The high rate of consent refusal for catheterisation $(37 \%)$ is worrying, particularly because consent is not usually obtained for this invasive procedure and because three patients who had refused consent for the trial subsequently required to be catheterised by the ward staff (presumably without obtaining formal consent). Our data on patient preference are limited but indicate that patients who are capable of stating a preference are evenly split between pads and catheters. In contrast, the majority of nurses did not like catheterisation and this may account in part for the rapid failure of catheters in the randomised patients, a finding which was in marked contrast to the generally good retention of catheters by patients who were catheterised outside the study protocol. An alternative explanation is that patients must be particularly dependent in order to tolerate catheterisation and that ward staff are good at identifying such patients.

Dissemination of the results of the study has led to some open discussion about the issues involved. In particular there is now wider recognition that urinary culture is not a diagnostic test for urinary infection in patients with chronic incontinence, whether managed with catheter or pads. If the majority of patients have asymptomatic bacteriuria, the diagnosis of invasive infection is a clinical one. The purpose of urinary culture must then be to select the best antimicrobial drug for treatment if required, and the result of culture has little input on the accuracy of diagnosis of urinary infection.

In conclusion, catheterisation reduces nursing time required for management of urinary incontinence and may reduce costs of equipment, depending on prevailing conditions for payment of laundry service. However, randomisation to catheters was associated with a high proportion of consent refusals and a high dropout rate in catheterised patients. These results and those of patients and nursing preference studies show that the decision to catheterise a patient must be made with the full support of medical or nursing staff and of the patient if it is to succeed. Our limited data suggest that the difference in rates of colonisation between catheterised and noncatheterised incontinent patients may not be as great as is generally supposed, but further studies are required to assess the harmful effects of urinary tract infection in catheterised patients.

The authors gratefully acknowledge the financial support of the Scottish Home and Health Department.

1 Yarnell JWG, Leger AS. The prevalence, severity and factors associated with urinary incontinence in a random sample of the elderly. Age Ageing 1979; 8: 81-5.

2 Warshaw GA, Morre JT, Friendman SW, et al. Functional disability in the hospitalised elderly. $\mathscr{J} A M A$ 1982; 248 847-50.

3 Ouslander JG, Kane RL, Abrass IB. Urinary incontinence in elderly nursing home patients. FAMA 1982; 248 : $1194-8$.

4 Willington FL. Problems in urinary incontinence in the aged. Gerontol Clin 1969; 11: 330-56.

5 Brocklehurst JC, Dillane JB, Griffiths L, Fry J. The prevalence and symptomatology of urinary infection in an prevalence and symptomatology of urinary infection 6 Resnick NM, Yalla SV. Management of urinary incontinence in the elderly. N Engl f Med 1985; 313: 800-5. Ory MG, Wyman JF, Yu L. Psychosocial factors in

incontinence. Clin Geriatr Med 1986; 2: 657-71.
Rannikko S, Kyllastinen M, Granqvist B. Comparison of Rannikko S, Kyllastinen M, Granqvist B. Comparison of
long-term indwelling catheters and bed-pads in the long-term indwelling catheters and bed-pads in the
treatment of urinary incontinence in elderly patients. $\mathcal{f}$ treatment of urinary inco
Infect 1986; 12: 221-7.

9 Schnelle JF, Sowell VA, Hu TW, Traughber B. Reduction of urinary incontinence in nursing homes: does it reduce or increase costs? ₹ Am Geriatr Soc 1988; 36: 34-9.

10 Resnick NM, Yalla SV, Laurino E. The pathophysiology of urinary incontinence among institutionalised elderly persons. N Engl f Med 1989; 320: 1-7.

11 Garibaldi RA, Burke JP, Dickman ML. Factors predisposing to bacteriuria during indwelling urethra catheterisation. $N$ Engl f Med 1974; 291: 215-9.

12 George RH, Johnson M, Young SD, Burdon DW. Induction of Clostridium difficile toxin by antibiotics. Cur Chemother Infect Dis 1979; 2: 955-6.

13 Kahn RL, Goldfarb AI, Pollack M, Peck A. Brief objective mear status in the aged. measures for the determination of men

14 Am f Psychiatry 1960; 117: 326-8. atz S, Ford AB, Moskowitz RW, Jackson BA, Jaffee MW. Studies of illness in the aged. The index of ADL: standardised measure of biological

15 Norton D, Exton Smith AN, McLaren R. An investigation Norton D, Exton Smith AN, McLaren R. An investigation of geriatric nursing problems in hospital. National Corporation for the Care of Old People,

16 Bender BS, Bennet R, Laughton BE, et al. Is Clostridium difficile endemic in chronic-care facilities? Lancet 1986; ii: difficile 